\title{
CORRESPONDENCE
}

\section{Choosing between batteries or biomass to stay on the road}

SIR - Nothing would please me more than to see batteries break out of their traditional markets and propel our cars, a goal described in your News Feature 'Charging up the future' (Nature 456, 436-440; 2008). In my view, this will not happen, however, because of the weakness of electrochemical power storage. The best lithium-ion battery provides energy at the rate of 100 watt-hours per kilogram. For liquid fuels such as petrol and diesel the energy density is around 12,000 watt-hours per kilogram. Even after dividing the latter figure by four because of Carnot-cycle losses in the conventional car engine, you are still at least 30 times better off with petrol than with the best and most expensive battery.

Would people be willing to pay significantly more for cars that perform worse than current versions? How likely are they to charge their batteries with 'green' power, which costs up to 10 times more than conventional electricity? The truth is that electric cars may fill a niche market for idealistic commuters, but for longer trips they are out of the question.

Synthetic fuels made of non-edible biomass are the best way to free cars of carbon dioxide emissions with existing technologies. Although the enzymes needed for splitting cellulose into sugar (the source of ethanol) are still much too expensive, the Fischer-Tropsch technology for making synthetic fuels from waste wood, straw or grass has been around for 70 years. Controlled burning with the addition of water yields a mixture of carbon monoxide and hydrogen that can be catalytically converted into any desired liquid fuel suitable for conventional internal-combustion engines.

The infrastructure for distributing such fuels is already in place. And enough biomass grows each year to supply the world's entire car fleet. Lucien F. Trueb In der Oberwis 9, 8123 Ebmatingen, Switzerland e-mail: lucien.trueb@bluewin.ch

\section{Genetic records threaten patients' privacy}

SIR - The philosophical issues involved in privacy of genetic data are debated in your Editorial 'My genome. So what?' (Nature 456, 1; 2008) and in Patrick Taylor's Commentary 'When consent gets in the way' (Nature 456, 32-33; 2008). But practical concerns are an issue too.

Hospitals increasingly often have electronic databases accessible by all doctors and nurses on the staff and some administrators. Someone who had had an abortion, for example, could find this information available to thousands. Privacy is likewise denied to cancer patients who don't want their illness to be common knowledge.

Penalties for snooping are hard to enforce. Medical information sneaks out, particularly about celebrities: anyone in medicine can find out exactly what type of pancreatic tumour afflicted Steve Jobs of Apple, as well as the details of his operation.

The FBI is currently investigating a criminal network allegedly trying to extort money from patients who used a medicalbenefits management company called Express Scripts; the company's computer records were, apparently, pilfered. People receiving medication for conditions such as herpesvirus were targeted.

Adding genetic information that can be interpreted in different ways will simply increase the exposure of patients to a system that is already faulty in practice.

Tom Goffman Cancer Intelligence and Research, 3830 Jefferson Boulevard, Virginia Beach, Virginia 23455, USA e-mail: tetomtg@yahoo.com

\section{Japan should intensify embryonic stem-cell investigations}

SIR - Your News story 'Japan ramps up patent effort to keep iPS lead' (Nature 453, 962-963; 2008) concerned research on human induced pluripotent stem (iPS) cells. For international research on these cells to progress, it is essential to have a thriving research programme on human embryonic stem (ES) cells.

However, the contribution to international research on ES cells between 1980 and 2006 by the United States and China was 20\% and $20.8 \%$, respectively, whereas Japan's was only $2.1 \%$ (see Japanese Ministry of Economy, Trade and Industry press release at http://tinyurl.com/6lphqw, in Japanese). If the Japanese government insists on having more restrictive regulations for human ES-cell research than other countries (see Nature 438, 263; 2005), Japan is in danger of being overtaken in the field of human iPS-cell research.

\section{Hisashi Moriguchi}

Laboratory for Systems Biology and Medicine, University of Tokyo, Japan, and Department of Analytical Health Science, Tokyo Medical and Dental University, Japan e-mail: moriguchi@lsbm.org Chifumi Sato Department of Analytical Health Science, Tokyo Medical and Dental University, Japan

\section{Research on primate brains is scrutinized and must be justified}

SIR - Ulrike Gross, in her Correspondence 'Public opinion and the ethics of primate brain research' (Nature 456, 443; 2008), says that monkey brain research similar to that conducted by Andreas Kreiter has been 'prohibited' in Zurich. This is not the case.

As reported in your News story 'Swiss court bans work on macaque brains' (Nature 453,
833; 2008), the Veterinary Office of the Canton of Zurich did grant licences for experiments involving macaques, but their decision was successfully challenged by some members of an advisory committee. These include the chair of the committee, Klaus Peter Rippe, who also chairs the Federal Ethics Committee on Non-Human Biotechnology that reported on the dignity of plants (Nature 453, 824; 2008).

The same Zurich advisory committee did not object to the granting of licences to other Zurich groups that used similar methods to Kreiter's. There is therefore no objection in principle to experiments with monkeys in Zurich.

The issue at present centres on the balance of cost and benefit, particularly on whether fundamental research is less valuable than applied research even when the former has longterm potential for contributing to human health and welfare. The Zurich case is currently under consideration by the Swiss Federal Court.

Gross says that the monkeys in Zurich are suffering. They are not, as the protocols of unannounced inspection visits by members of the cantonal Veterinary Office advisory committee affirm.

She also says, "Even a prominent scientist such as Andreas Kreiter must justify his use of animals". In Europe there are many levels at which such justification is required: the research institutions, the funding organizations, the licensing authorities (where her interests are usually represented), and the journals where the research is peer reviewed. In our society, science is the activity that is probably subject to the widest scrutiny and review by both experts and laypeople alike.

Kevan A. C. Martin Institute of Neuroinformatics, UZH/ETH, Winterthurerstrasse 190, 8057 Zurich, Switzerland tocorrespondence@nature.com. 